Article

\title{
Fluorosilicone as an Omnimold for Microreplication
}

\author{
Teng Zhang ${ }^{1,2}$, Xiaokui Yue ${ }^{2}$ and Dan Sameoto ${ }^{1, *}$ \\ 1 Department of Mechanical Engineering, University of Alberta, Edmonton, AB T6G 2G8, Canada; \\ tzhang1@ualberta.ca \\ 2 National Key Laboratory of Aerospace Flight Dynamics, Northwestern Polytechnical University, \\ Xi'an 710072, China; xkyue@nwpu.edu.cn \\ * Correspondence: sameoto@ualberta.ca; Tel.: +1-780-248-2052
}

Received: 19 July 2018; Accepted: 10 August 2018; Published: 16 August 2018

\begin{abstract}
Soft lithography and replica molding have been an integral part of polymer basic microfabrication for over 20 years. The use of silicone rubber materials as either molds or directly molded parts are well described in the literature and have provided researchers with an easily accessible technique to reproduce complex micro and nanostructures with minimal costs and technical challenges. Yet, for many applications, the use of standard silicones may not necessarily be the best choice, either as a mold material or as a replicated surface. For those instances where a mold is required that is high temperature tolerant, flexible, durable and capable of being used as a mold for multiple materials including silicone rubber, the most commonly used silicone rubber, Sylgard-184, has substantial deficiencies. In this work, we introduce a new material, Fluorosilicone that has not been described in the microfabrication field in detail and determine it is capable of reproducing micro structures via soft lithography techniques and being used as a mold for thermoplastic and thermosetting polymers, including silicone rubbers. Material compatibility, appropriate processing conditions for quality replicas and demonstration of extremely fast production of silicone microstructures are reported.
\end{abstract}

Keywords: fluorosilicone; soft lithography; molding; adhesion; silicone; polyurethane; casting

\section{Introduction}

In some applications of microfabrication, like microfluidic devices or gecko-like adhesives, fabrication of polymer-based samples via soft lithography including hot embossing, injection molding, or lamination, is widely applied [1-4]. Compared with standard lithography, many self-lithography processes can be done outside a cleanroom, which reduces the cost and complexity, and large-scale production is possible. The key part in the fabrication process is the production of a high quality negative mold with desired structures [5].

When rigid molds are used, the mold material ought to have some specific properties [5]: (i) High stiffness and strength, (ii) good physical and chemical resistance, (iii) easy to be fabricated with different structures, and (iv) low surface energy for aid in demolding. Generally, there are two kinds of molds-rigid and soft molds. Compared with rigid molds, like SU-8 (MicroChem, Worcester, MA, USA) on Si wafers or Poly methyl methacrylate (PMMA, Plaskolite, Columbus, OH, USA) substrates, soft molds fabricated by Polydimethylsiloxane (PDMS) or other elastomers typically can have longer life cycles, because the thermal or demolding stress does not affect the mold but for rigid ones, structures may be damaged in curing or demolding [6]. Moreover, soft molds permit molding to be completed on non-flat surfaces or be more easily adapted to roller style continuous molding processes. Of the materials that can be used to make soft molds, PDMS is often selected due to its good physical and chemical properties, and its ease of fabrication outside a cleanroom environment, which reduces 
the time, complexity, and cost $[7,8]$. However, PDMS has some disadvantages that limit its applications in fabricating soft molds:

- Its tear strength can be low (about $0.87 \mathrm{kN} / \mathrm{mm}$ for Dow Corning ${ }^{\circledR}$ Sylgard-184), so it is easy to rip and is challenging to obtain a thin mold;

- When PDMS structural material for the final product is required, surface modification of the mold is required to achieve anti-sticking behavior [6];

- PDMS will swell in some organic solvents [7,9], which makes several types of solvent casting unfeasible.

Fluorosilicone is an elastomer of siloxane polymers with fluorinated organic substituents bonded to silicon, which can be used in extreme environments and may resist damage/deformation when in contact with various chemicals that regular silicone rubbers cannot [10]. According to literature, most research on fluorosilicone is about its composition and fabrication [11-15] and its applications in the fields of fuels, oils, injection molding as O-rings, releasing or coating layers [16-22]. However, in the field of microelectromechanical systems (MEMS), microfluidics or microfabrication in general, fluorosilicone has not been investigated yet, especially the use of fluorosilicone as a material in soft lithography for durable, flexible and high temperature tolerant molds.

Several important properties of a commonly used PDMS (Dow Corning ${ }^{\circledR}$ Sylgard-184, Midland, MI, USA) and an investigated fluorosilicone (Dow Corning ${ }^{\circledR}$ 5-8601 Fluorosilicone, Midland, MI, USA) are compared in Table 1. They have the same hardness, and PDMS has larger tensile modulus, but the fluorosilicone has a much larger tear strength (about 23 times that of PDMS), and longer pot life at room temperature ( $96 \mathrm{~h}$ vs. $1.6 \mathrm{~h}$ ). Additionally, fluorosilicone is more resistant to organic solvents [10] which can be a benefit in specific soft lithographic processes like solvent assisted micromolding.

Table 1. Comparison of Sylgard-184 and 5-8601 fluorosilicone.

\begin{tabular}{cccc}
\hline Property & \multirow{2}{*}{ Unit } & \multicolumn{2}{c}{ Materials } \\
\cline { 3 - 4 } & & PDMS & Fluorosilicone \\
\hline Elongation & $\%$ & 120 & 350 \\
Tear strength & $\mathrm{kN} / \mathrm{mm}$ & 0.87 & 20 \\
Tensile modulus & $\mathrm{MPa}$ & 7.1 & 6.2 \\
Durometer Shore A & points & 44 & 45 \\
Pot life at room temperature & hours & 1.4 & 96 \\
\hline
\end{tabular}

Note: The data of Dow Corning ${ }^{\circledR}$ Sylgard-184 and Dow Corning ${ }^{\circledR}$ 5-8601 fluorosilicone in References [23,24] are compared here. More details about the Dow Corning ${ }^{\circledR} 5-8601$ fluorosilicone can be found in References $[25,26]$.

This paper investigates the usage of fluorosilicone in soft lithography in terms of compatibility with a range of master mold materials and castable structural materials from the fluorosilicone. Both unstructured and highly structured dry adhesive molds are used for molding compatibility trials. The master mold materials tested for releasing negative fluorosilicone replicas include; PMMA, SU-8, silicon wafer (Silicon Materials, Glenshaw, PA, USA), glass, polylactic acid (PLA, Filaments.ca, Mississauga, Ontario, Canada), Kraton ${ }^{\circledR}$ G1657 styrene ethylene butylene styrene (SEBS, Kraton, Houston, TX, USA), shape memory polymer (SMP, MM-2520, SMP Technologies Inc, Tokyo, Japan), polystyrene (PS, Fisher Scientific, Hampton, NH, USA), PDMS (BJB Enterprise ${ }^{\circledR}$ TC-5030, BJB Enterprises, Tustin, CA, USA; and Dow Corning ${ }^{\circledR}$ Sylgard-184, Dow Corning). To cast thin fluorosilicone molds on master templates, we use a modified lamination process due to the extremely high viscosity of the uncured fluorosilicone. Lamination can be done at room temperatures for example, while for injection, the mold should be heated to between $170{ }^{\circ} \mathrm{C}$ and $220^{\circ} \mathrm{C}$ [26]. Once high quality fluorosilicone negative molds are produced, the molding and demolding properties of different thermoplastic and thermosetting polymers on the flat and negative featured fluorosilicone mold are tested. The results show that nearly all the polymers in the experiment can be fully cured and demolded well from the fluorosilicone 
negative mold. As a demonstration of usefulness of fluorosilicone as a soft lithography mold in production applications, a Sylgard-184 replica of dry adhesive fibers has been cured in as little as a minute without vacuum degassing from a fluorosilicone negative template. This dramatically reduces time and complexity of manufacturing of silicone rubber microstructured surfaces.

\section{Fabrication Process}

Dow Corning ${ }^{\circledR}$ 5-8601 Fluorosilicone Liquid Silicone Rubber, is designed for liquid injection molding [24] and is used and tested in this work as a representative material because it had the lowest viscosity of the fluorosilicones available to us. The product is supplied as a two-component reaction cure system that is mixed at a 1:1 ratio. Due to the high viscosity of fluorosilicone as shown in Figure 1f, traditional soft lithography methods for making silicone rubber molds cannot be used. Instead, a lamination method, adapted from previous work [27] is applied. The fabrication process after mixing and degassing is shown in Figure 1a-e. A planetary mixer is normally recommended to avoid introducing air bubbles into the viscous fluorosilicone paste but as this equipment was unavailable, a telfon coated steel rod was used to hand mix the material. Then the mixed fluorosilicone is degassed for $24 \mathrm{~h}$, at $\sim 5$ $\mathrm{kPa}$, to remove as much air as possible. After that, it is transferred to the mold with a spatula, and a transparency film (3M ${ }^{\circledR}$ PP2910 Plain Paper Copier Transparency Film, The 3M Company, Maplewood, MN, USA) is lightly pressed on the fluorosilicone to provide a relatively flat backing. The whole stack is then placed in a Ziploc bag and then run through a laminator at room temperature with progressively smaller gaps between rollers until a relatively uniform fluorosilicone layer is achieved. Then, the fluorosilicone with the mold and the film is cured at $80^{\circ} \mathrm{C}$ for $96 \mathrm{~h}$. The fluorosilicone and the film is demolded from the mold, and they are cured at $150{ }^{\circ} \mathrm{C}$ again for $30 \mathrm{~min}$. Finally, after peeling off the film from the fluorosilicone mold, a post-cure is done at $200{ }^{\circ} \mathrm{C}$ for at least $30 \mathrm{~min}$.

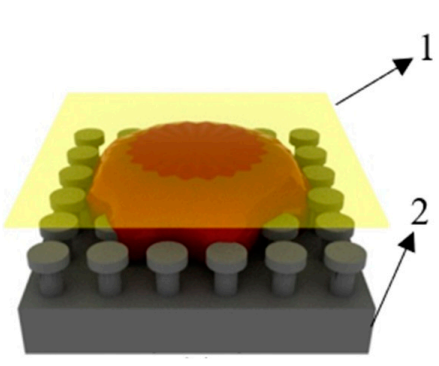

(a)

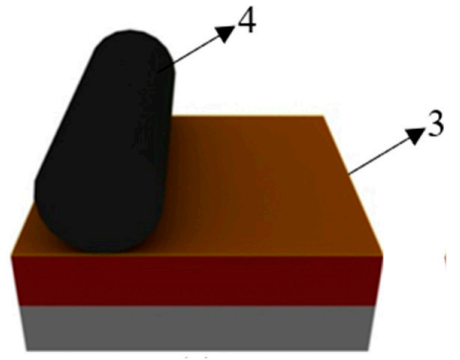

(b)

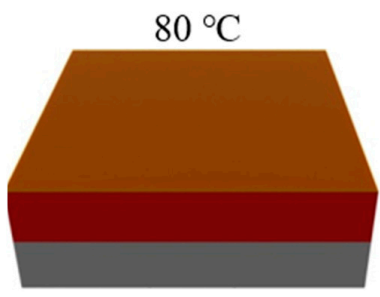

(c) $150{ }^{\circ} \mathrm{C}$

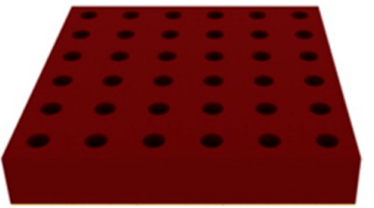

(d)

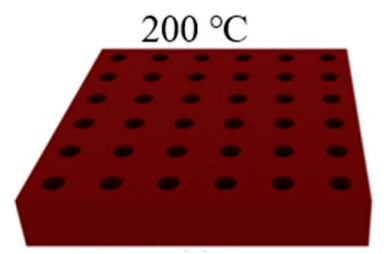

(e)

Figure 1. Fabrication process of making fluorosilicone mold. 1: Thin film; 2: mold; 3: fluorosilicone; 4: roller; (a) The film is coved on fluorosilicone with the mold; (b) Modified lamination; (c) Curing at $200{ }^{\circ} \mathrm{C}$; (d) Curing at $150{ }^{\circ} \mathrm{C}$ after demolding; (e) Post-curing at $200{ }^{\circ} \mathrm{C}$ after the film is peeled off; (f) Photo of fluorosilicone after mixing. 
In Table 2, residual ratio is defined as the ratio between the area of the residual fluorosilicone after demolding and the area of the mold initially covered by the fluorosilicone. The molds which can be demolded but with residuals after demolding are shown in Figure 2. The scale bars in Figure 2 represent a distance of $1 \mathrm{~cm}$.

Table 2. Results of demolding fluorosilicone from different molds.

\begin{tabular}{|c|c|c|c|c|}
\hline Materials & Mold Category & Ease of Demolding & Residual Ratio & Notes \\
\hline PMMA & Flat & ++ & Not observable & $\begin{array}{l}\text { Easy to demold, works } \\
\text { well }\end{array}$ \\
\hline Silanized glass & Flat & ++ & Not observable & $\begin{array}{l}\text { Easy to demold, works } \\
\text { well }\end{array}$ \\
\hline Glass & Flat & - & $\sim 5 \%$ & $\begin{array}{l}\text { Residual fluorosilicone } \\
\text { on the glass }\end{array}$ \\
\hline Silanized silicon wafer & Flat & ++ & Not observable & $\begin{array}{l}\text { Easy to demold, works } \\
\text { well }\end{array}$ \\
\hline Silicon wafer & Flat & - & $100 \%$ & Impossible to demold \\
\hline SU-8 & Structured & ++ & Not observable & $\begin{array}{l}\text { Easy to demold, works } \\
\text { well }\end{array}$ \\
\hline PLA & Structured & + & $\sim 5 \%$ & $\begin{array}{l}\text { The top surface of the } \\
\text { PLA looks rough after } \\
\text { demolding }\end{array}$ \\
\hline SEBS & Structured & - & $\sim 40 \%$ & $\begin{array}{l}\text { SEBS mold is damaged } \\
\text { in demolding }\end{array}$ \\
\hline Polystyrene & Structured & ++ & Not observable & $\begin{array}{l}\text { Easy to demold, works } \\
\text { well }\end{array}$ \\
\hline SMP & Structured & - & $\sim 50 \%$ & $\begin{array}{l}\text { Residual fluorosilicone } \\
\text { on the SMP mold }\end{array}$ \\
\hline TC-5030 & Structured & - & $100 \%$ & Impossible to demold \\
\hline Sylgard-184 & Structured & - & $\sim 30 \%$ & $\begin{array}{l}\text { Residual PDMS on the } \\
\text { fluorosilicone mold }\end{array}$ \\
\hline
\end{tabular}

++. very easy; +: easy; -: difficult; -: Impossible; PLA = polylactic acid; SEBS = styrene ethylene butylene styrene; $\mathrm{SMP}=$ shape memory polymer.

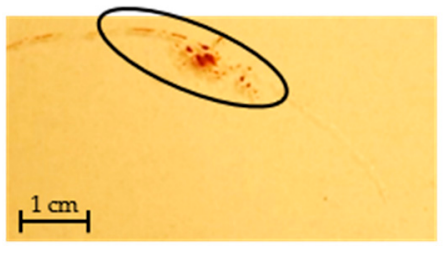

(a)

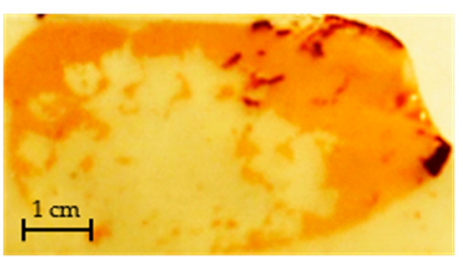

(d)

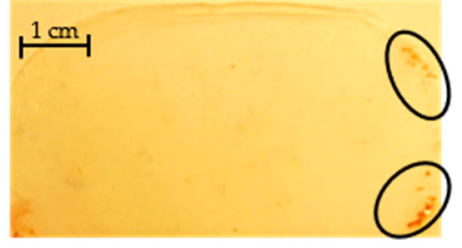

(b)

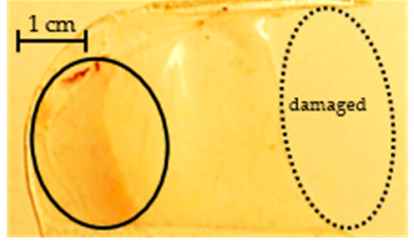

(c)

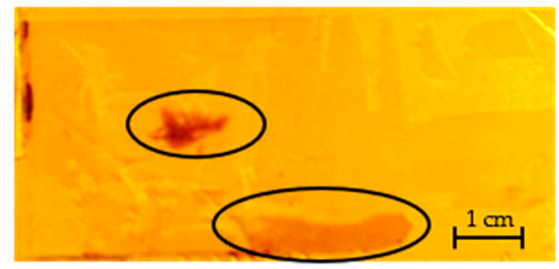

(e)

Figure 2. Residuals on the different molds after demolding. In the above figures, except for Figure $2 \mathrm{~d}$, the residuals are all circled. In Figure $2 \mathrm{c}$, the dash circle represents the area that is damaged in demolding. (a) Glass; (b) PLA; (c) SEBS; (d) SMP; (e) Sylgard-184.

For the flat molds, fluorosilicone can be demolded well from the silanized glass, silianized silicon, and PMMA with no residuals observed. It is impossible to demold fluorosilicone from the bare silicon wafer and demolding from glass is possible but leaves substantial residual material as shown in Figure 2a. Generally, silane treatment is beneficial for making the fluorosilicone mold and the fluorosilicone adhesive behavior is similar to PDMS in this respect. 
For the positive molds, only SU-8 and PS structural materials show good performance with no residuals being left after fluorosilicone is demolded. For other master molds, some fluorosilicone is left, and in the case of SEBS, the mold is heavily damaged after use.

To examine the microscale fidelity of the fluorosilicone negative molds, the corresponding PS duplications from PS, PLA, SEBS, SMP, and Sylgard-184 molds are fabricated by compression molding and SEM images of typical features are shown in Figure 3. Because fluorosilicone is left on some parts of the molds with the exception of the PS positive, only the areas of fluorosilicone that cleanly demolded are used for making the imaging replicas.

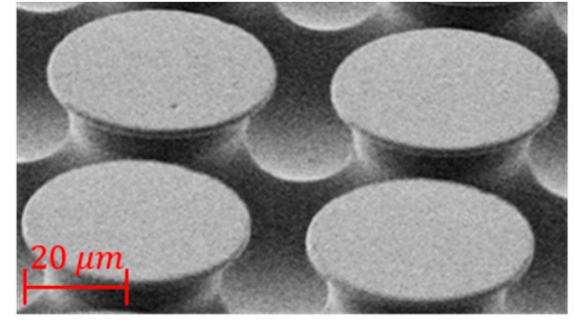

(a)

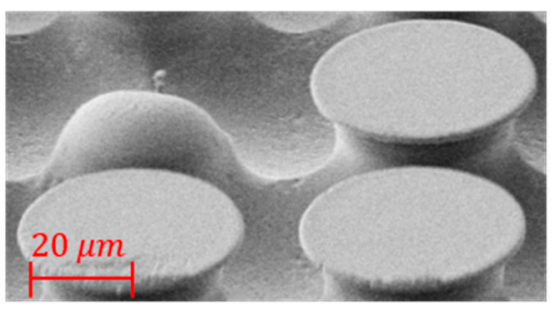

(c)

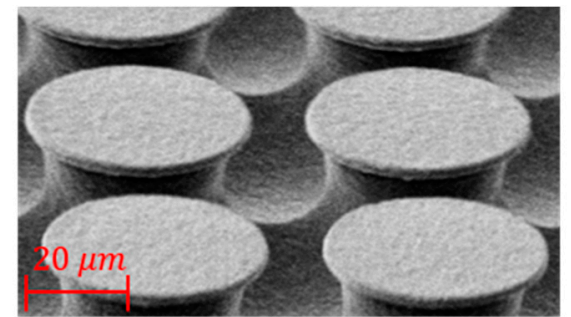

(b)

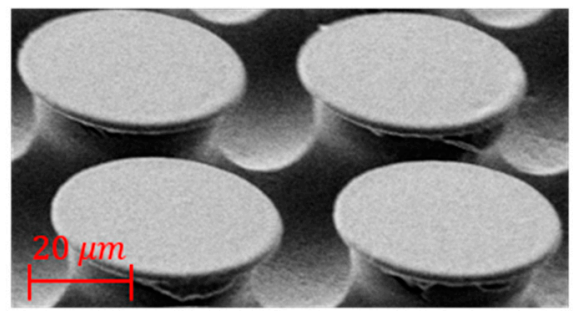

(d)

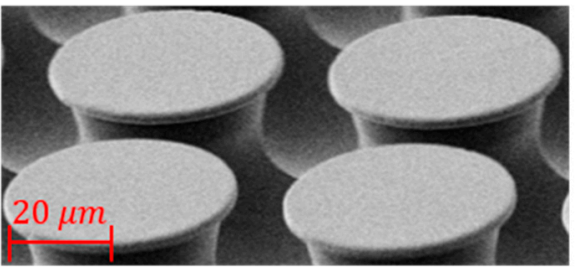

(e)

Figure 3. Scanning electron microscope (SEM) samples of polystyrene (PS) replicas from the fluorosilicone mold. (a) Duplications from the PS master mold. (b) Duplications from the PLA master mold. (c) Duplications from the SEBS master mold. (d) Duplications from the SMP master mold.

(e) Duplications from the Sylgard-184 master mold.

In Figure 3, all the scale bars represent $20 \mu \mathrm{m}$. For the duplication from the PS mold, the fibers are high quality, and the surfaces are smooth as in Figure 3a. In contrast with the SU-8 mold, the PS mold can be fabricated by hot embossing outside the cleanroom, which decreases the time consumption and cost and shows good potential for fast and massive production. For the duplication from the PLA mold, the fibers look acceptable, but the top surfaces are rough as seen in Figure $3 b$. For the replicas from the SEBS and SMP master mold in Figure 3c,d, the fibers look damaged, even though they are from good areas of the mold. While for duplications from the Sylgard-184 master mold, the fibers look the same quality as the fibers from the PS master mold as shown in Figure 3a,e. For Sylgard-184 and TC-5030, both of them are PDMS, but they show different performance. Fluorosilicone mold can be demolded from the master Sylgard-184 mold although some residuals are left, but fluorosilicone is bonded permanently with TC-5030 after it is fully cured. 


\section{Fluorosilicone as a Negative Mold for Soft-Lithography Replication}

After the high quality fluorosilicone mold is fabricated, its usefulness as a negative mold for replicating different structural materials is tested. Many thermosetting and thermoplastic rubbers and hard polymers used by our group are tested for compatibility with fluorosilicone molds, including Dow Corning ${ }^{\circledR}$ 93-500 (Dow Corning), ECO-Flex ${ }^{\mathrm{TM}}$ 00-10 (Smooth-on, Macungie, PA, USA), Dow Corning 7-9850 (Dow Corning), Dragon skin ${ }^{\circledR} 30$ (Smooth-on,), Dow Corning ${ }^{\circledR}$ MS-1002 (Dow Corning), polyurethane (PU, Normac ${ }^{\circledR}$ NR-906, Normac Adhesive Products Inc., Burlington, ON, Canada), Chronoprene 5A (AdvanSource ${ }^{\circledR}$ biomaterials, Wilmington, MA, USA), PS (Fisher Scientific), SEBS (Kraton ${ }^{\circledR}$ G1657), SMP (SMP Technologies Inc), PDMS (TC-5030, and Sylgard-184), 3M ${ }^{\mathrm{TM}}$ ESPE ${ }^{\mathrm{TM}}$ Imprint $^{\mathrm{TM}} 3$ Regular Body (The 3M Company) and Momentive RTV 159 silicone adhesive (Momentive, New York, NJ, USA).

All these materials have specific processing conditions and methods that are best suited for their replication from fluorosilicone molds, but manufacturing techniques used fall under compression molding, vacuum casting and lamination as shown in Figure 4. Compression molding was completed for thermoplastics and thermoplastic elastomers at $220^{\circ} \mathrm{C}$, with a load of approximately $0.5 \mathrm{MPa}$ using a process described previously for silicone rubber molds [28]. Vacuum casting was done with thermosetting materials that had relatively low viscosities and was done according to material recommendations, and lamination was completed for thermosetting materials that cured exceptionally fast or had viscosities too high to work with vacuum casting. Some important properties of the materials used in these experiments are listed in Table 3.

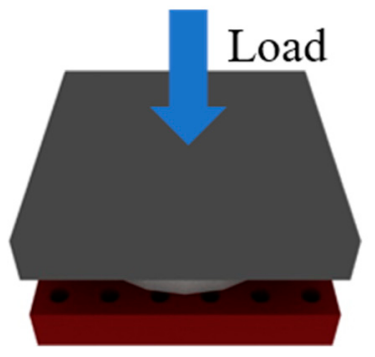

(a)

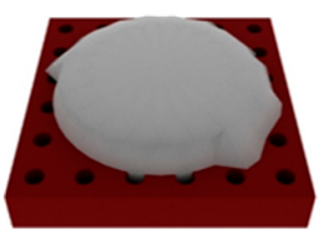

(b)

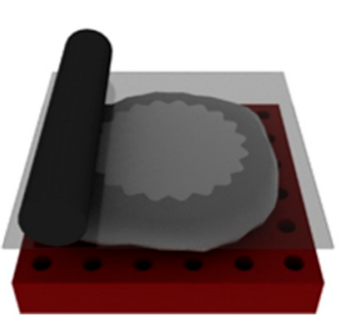

(c)

Figure 4. Fabrication processes used to produce polymer samples from fluorosilicone molds. (a) Hot embossing; (b) vacuum; and (c) lamination.

The qualitative results on demolding yields are listed in Table 4. For Sylgard-184, due to its low tear strength, a Kapton ${ }^{\circledR}$ polyimide tape (DuPont, Wilmington, DE, USA) with silicone adhesive is gently placed on the uncured PDMS after vacuum degassing. After being fully-cured, the Sylgard-184 sample with the tape is demolded together from the mold. 
Table 3. Properties of materials used for replicas from fluorosilicone masters.

\begin{tabular}{|c|c|c|c|c|}
\hline Polymers & Type & Fabrication Method & Hardness & Link \\
\hline Chronoprene 5A & Thermoplastic & $\mathrm{C}$ & $5 \mathrm{~A}$ & $\begin{array}{l}\text { http://www.advbiomaterials.com/products/ } \\
\text { elastomeric/chronoprene.html }\end{array}$ \\
\hline Dow Corning 93-500 & Silicone rubber & $\mathrm{V}$ & $46 \mathrm{~A}$ & $\begin{array}{l}\text { http://www.centralcoating.com/wp-content/ } \\
\text { uploads/2014/11/93-500.pdf }\end{array}$ \\
\hline ECO-Flex & Silicone rubber & $\mathrm{V}$ & $00-10$ & $\begin{array}{l}\text { https://www.smooth-on.com/tb/files/ECOFLEX_ } \\
\text { SERIES_TB.pdf }\end{array}$ \\
\hline Dow Corning ${ }^{\circledR}$ MG 7-9850 & Silicone rubber & $\mathrm{V}$ & $\mathrm{N} / \mathrm{A}$ & $\begin{array}{l}\text { http: } \\
\text { //www.healthcare-plus.com.tw/big5/pdf/02-05.pdf }\end{array}$ \\
\hline PS & Thermoplastic & $\mathrm{C}$ & $\mathrm{N} / \mathrm{A}$ & $\mathrm{N} / \mathrm{A}$ \\
\hline SEBS & Thermoplastic & $\mathrm{C}$ & $47 \mathrm{~A}$ & $\begin{array}{l}\text { http://www.talasonline.com/images/PDF/ } \\
\text { ProductDataSheet/Kraton_G1657_datasheet.pdf }\end{array}$ \\
\hline SMP & Thermoplastic & $\mathrm{C}$ & $30 \mathrm{D}$ & http://www2.smptechno.com/en/smp/ \\
\hline PU & Thermoset & $\mathrm{V}$ & $85-90 \mathrm{~A}$ & $\begin{array}{l}\text { http://www.normacadhesives.com/fr/normac- } \\
\text { products/castable/nr-906.html }\end{array}$ \\
\hline Sylgard-184 & Silicone rubber & $\mathrm{V}$ & $43 \mathrm{~A}$ & $\begin{array}{l}\text { https://consumer.dow.com/content/dam/dcc/ } \\
\text { documents/en-us/productdatasheet/11/11-31/11- } \\
\text { 3184-sylgard-184-elastomer.pdf?iframe=true }\end{array}$ \\
\hline TC-5030 & Silicone rubber & $\mathrm{V}$ & $25-35 \mathrm{~A}$ & $\begin{array}{l}\text { https://bjbenterprises.com/media/wysiwyg/pdfs / } \\
\text { Silicones/TC-5030.pdf }\end{array}$ \\
\hline Dragon Skin ${ }^{\circledR} 30$ & Silicone rubber & $\mathrm{V}$ & $30 \mathrm{~A}$ & $\begin{array}{l}\text { https://www.smooth-on.com/tb/files/DRAGON_ } \\
\text { SKIN_SERIES_TB.pdf }\end{array}$ \\
\hline MS-1002 & Silicone rubber & $\mathrm{V}$ & $74 \mathrm{~A}$ & $\begin{array}{l}\text { https://www.protolabs.co.uk/media/751887/dow_- } \\
\text { corning_electronics_ft_ms-1002.pdf }\end{array}$ \\
\hline 3 Regular Body & Silicone rubber & $\mathrm{L}$ & $55 \mathrm{~A}$ & $\begin{array}{l}\text { http://multimedia.3m.com/mws/media/391881O/ } \\
\text { imprint-3-vps-impression-materials.pdf }\end{array}$ \\
\hline RTV 159 adhesive & Silicone rubber & $\mathrm{L}$ & $28 \mathrm{~A}$ & $\begin{array}{l}\text { https://www.momentive.com/en-us/products/tds/ } \\
\text { rtv157-and-rtv159/ }\end{array}$ \\
\hline
\end{tabular}

$\mathrm{C}=$ compression molding; $\mathrm{V}=$ vacuum $; \mathrm{L}=$ lamination; $\mathrm{PU}=$ polyurethane 
Table 4. Results of peeling polymers from fluorosilicone molds after being cured.

\begin{tabular}{|c|c|c|c|}
\hline Polymers & Flat Mold & Negative Mold & Note \\
\hline Chronoprene $5 \mathrm{~A}$ & Work & $\begin{array}{l}\text { Too soft to form stable } \\
\text { structures }\end{array}$ & Not difficult to demold \\
\hline $\begin{array}{l}\text { Dow Corning }^{\circledR} \\
93-500\end{array}$ & Work & $\begin{array}{l}\text { Too soft to form stable } \\
\text { structures }\end{array}$ & $\begin{array}{l}\text { Difficult to demold even for the flat } \\
\text { mold, although it is cured well }\end{array}$ \\
\hline ECO-Flex $^{\mathrm{TM}} 00-10$ & Work & $\begin{array}{l}\text { Too soft to form stable } \\
\text { structures }\end{array}$ & The same as Chronoprene 5A \\
\hline MG 7-9850 & Work & $\begin{array}{l}\text { Too soft to form stable } \\
\text { structures }\end{array}$ & The same as Dow Corning ${ }^{\circledR} 93-500$ \\
\hline PS & Work & Work & Works well and very easy to demold \\
\hline SEBS & Work & Work & The same quality as PS \\
\hline SMP & Work & Work & $\begin{array}{c}\text { The same quality as PS, although more } \\
\text { difficult to compression mold }\end{array}$ \\
\hline PU & Work & Work & The same as PS \\
\hline Sylgard-184 & Work & Work & $\begin{array}{l}\text { Kapton polyimide tape is needed to } \\
\text { demold without tearing. Good quality } \\
\text { samples can be obtained with tape or } \\
\text { with thicker PDMS }\end{array}$ \\
\hline TC-5030 & Work & Work & $\begin{array}{c}\text { When cured too long, the fibers are } \\
\text { damaged after peeling off }\end{array}$ \\
\hline Dragon Skin ${ }^{\circledR} 30$ & Work & Work & $\begin{array}{c}\text { Good performance when being cured at } \\
\text { room temperature }\end{array}$ \\
\hline MS-1002 & Work & Work & $\begin{array}{l}\text { Good performance, but due to its low } \\
\text { tear strength, easy to be broken }\end{array}$ \\
\hline 3 Regular Body & Work & Work & Good performance \\
\hline RTV 159 adhesive & Work & Failed & $\begin{array}{l}\text { Good performance for the flat mold, but } \\
\text { failed to negative mold }\end{array}$ \\
\hline
\end{tabular}

All the thermosetting polymers in the experiment can be cured with no evidence that the fluorosilicone inhibits the cure in any way. For the very soft materials, the fibers are damaged when being demolded from the negative mold. Some of them, including Dow Corning ${ }^{\circledR}$ 93-500 and Dow Corning ${ }^{\circledR}$ MG 7-9850, are so soft that they are difficult to be demolded even from the flat mold, but they are fully cured and can be demolded without leaving residue. Chronoprene $5 \mathrm{~A}$ and ECO-Flex ${ }^{\mathrm{TM}}$ 00-10, do not pose difficulties to demold from the flat mold. For the polymers which are stiffer than Ecoflex 00-10, almost all of them can be demolded from both the flat and negative mold with the exception of RTV 159 adhesive. which is used as a high strength silicone rubber sealant. So, it is not strange to see that it is bonded strongly to the negative mold.

Ideally, a fluorosilicone mold would work with every material that demolds from it without issue, but unfortunately other factors can play a role. For example, addition curable PDMS like Sylgard-184 cannot be cured on soft polyurethane molds because of inhibition of the crosslinking agent in PDMS by the polyurethane. While fluorosilicone molds work for both polyurethane and Sylgard-184, the same mold was found to not be compatible with each due to residual PU diffusing into the fluorosilicone. This was confirmed by running the experiment shown in Figure 5. PU is cast on part of a fluorosilicone mold, cured and then demolded. After demolding the PU, Sylgard-184 is cast on the whole mold. The Sylgard-184 is cured at $80^{\circ} \mathrm{C}$ for $2 \mathrm{~h}$ and then examined by probing with an applicator stick. Touching the PDMS demonstrated that the material was still liquid on the portion of the mold previously covered with PU (areas A and B), and solid everywhere else (areas C and D). The video (Video S1) shows the results. 

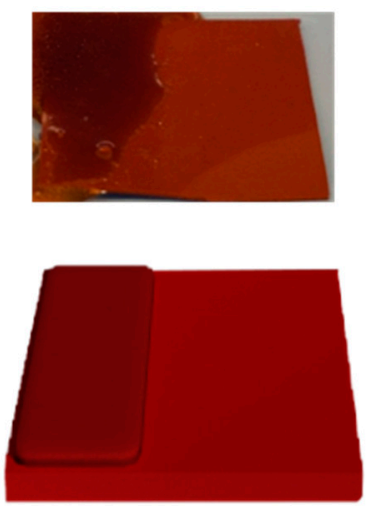

(a)
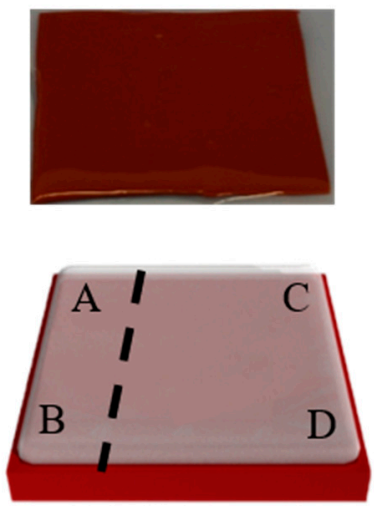

(b)
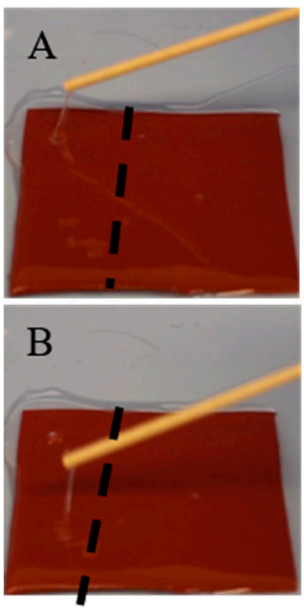
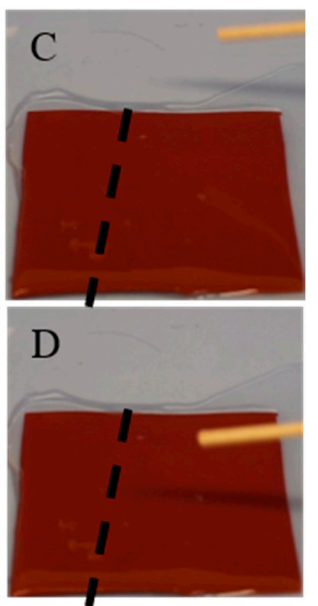

Figure 5. Experiment of PU on the fluorosilicone mold (the dash line represents the edge of PU, on the left of the line, PU is cured on and demolded from the mold). Left: (a) PU on the part of the mold, (b) Sylgard-184 on the whole mold after PU is demolded; Right: The photos after the applicator contacts to the different areas as in $(\mathbf{b})$.

\section{Discussion}

One of the limitations to fast and inexpensive processes using soft lithography is the time to cure the silicones (often an hour or more for many applications). The higher temperature tolerances and durability of fluorosilicone offer a way around this limitation. Fluorosilicone molds can work at up to $225^{\circ} \mathrm{C}$ [24] in dry environments, so a trial to determine the feasibility of quick curing Sylgard-184 at $200{ }^{\circ} \mathrm{C}$ was completed. The soft mold is damage resistant, so PDMS can be spread into the holes with a light pressure applied by a glass rod and microscale fibers are replicated without the need for vacuum degassing. A video recording of the trial is shown in the supplementary information (Video S2) and some key points of the video are shown in Figure 6. After mixing and degassing, the liquid PDMS is gently rubbed onto a fluorosilicone mold and then transferred to a hotplate held at $200{ }^{\circ} \mathrm{C}$. The sample was solidified within a minute and then the mold is removed from the hot plate. The sample cools to room temperature within $30 \mathrm{~s}$, at which point the sample is demolded and inspected under a microscope. In total, the time from dispensing to completion is approximately $2 \mathrm{~min}$. For Sylgard-184, the sample should normally be cured for over $48 \mathrm{~h}$ at room temperature or $2 \mathrm{~h}$ at $80^{\circ} \mathrm{C}$. The high temperature tolerance and mechanical durability of a fluorosilicone mold permits silicone casting to be completed orders of magnitude more quickly than traditional molding, and because fluorosilicone mold is soft and flexible it can be used to thermal roll to roll nanoprinting system for massive production, as in Reference [29].

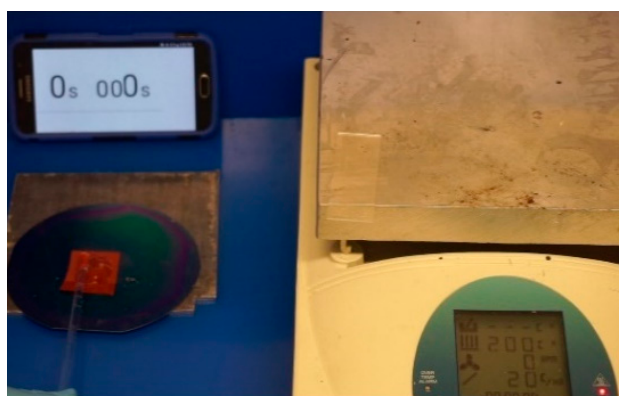

(a)

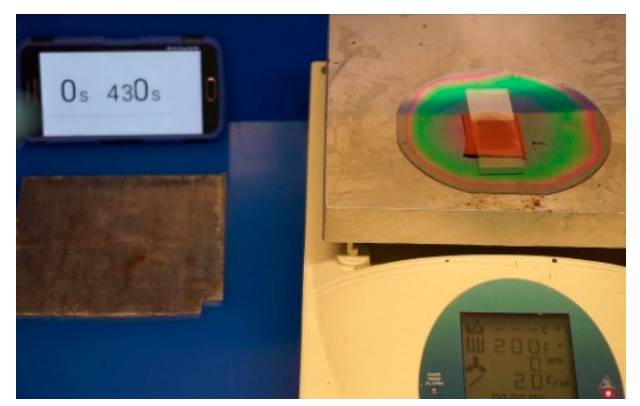

(b)

Figure 6. Cont. 


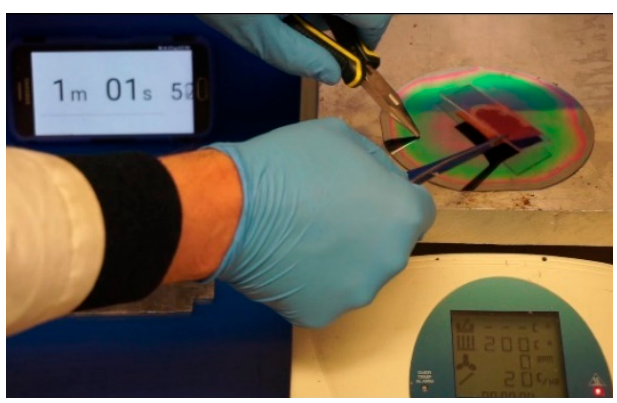

(c)

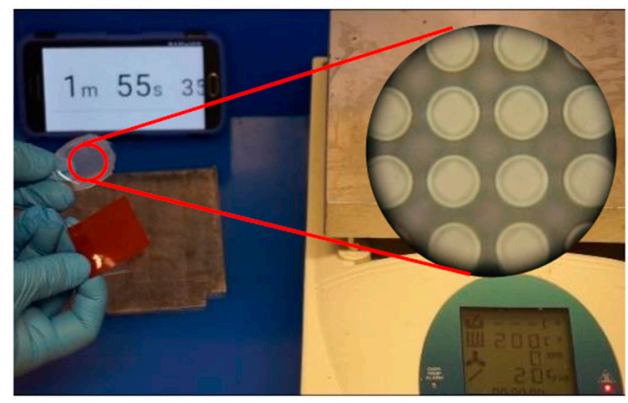

(d)

Figure 6. Flash curing of PDMS samples via fluorosilicone mold: (a) Sylgard-184 is rubbed on the fluorosilicone mold; (b) Sylagrd-184 is heated at $200{ }^{\circ} \mathrm{C}$; (c) the sample is removed after $1 \mathrm{~min}$; (d) the sample is demolded and inspected.

\section{Conclusions}

Fluorosilicone has been introduced as a mold material for soft lithography. Compared with rigid molds, soft molds can be more mechanically durable, and this particular material is usable with a very wide range of castable and thermally moldable materials. While more challenging to produce high quality initial templates from lithographically patterned molds, the high temperature tolerance, and good mechanical durability of fluorosilicone makes it an excellent choice for fast casting of commonly used silicone rubber materials like Sylgard-184. Light mechanical pressure can be used to fill in arrays of gecko-inspired adhesive fibers and the flexible nature of fluorosilicone means that continuous manufacturing of micro or nanostructured PDMS surfaces may be commercially viable in roll-to-roll processes because curing can be accelerated by orders of magnitude when using fluorosilicone as a mold material.

Supplementary Materials: The following are available online at http:/ /www.mdpi.com/2072-666X/9/8/406/s1. Video S1: Experiment of PU on the fluorosilicone mold. Video S2: Flash curing of PDMS samples via fluorosilicone mold.

Author Contributions: T.Z. and D.S. conceived and designed the experiments; T.Z. performed the experiments. All the authors wrote, reviewed and modified the paper.

Funding: This research received no external funding.

Acknowledgments: The authors thank Dongchan (Shaun) Ahn from Dow Corning Corporation for providing the fluorosilicone and several other silicon, and Natural Sciences and Engineering Research Council (NSERC) and the China Scholarship Council for the financial support of the work presented.

Conflicts of Interest: The authors declare no conflict of interest.

\section{References}

1. McCormick, R.M.; Nelson, R.J.; Alonso-Amigo, M.G.; Benvegnu, D.J.; Hooper, H.H. Microchannel electrophoretic separations of DNA in injection-molded plastic substrates. Anal. Chem. 1997, 69, 2626-2630. [CrossRef] [PubMed]

2. Lan, S.; Lee, H.J.; Kim, E.; Ni, J.; Lee, S.H.; Lai, X.; Song, J.H.; Lee, N.K.; Lee, M.G. A parameter study on the micro hot-embossing process of glassy polymer for pattern replication. Microelectron. Eng. 2009, 86, 2369-2374. [CrossRef]

3. Zandvakili, M.; Honari, M.M.; Mousavi, P.; Sameoto, D. Gecko-Gaskets for multilayer, complex, and stretchable liquid metal microwave circuits and antennas. Adv. Mater. Technol. 2017, 2, 1700144. [CrossRef]

4. Soltannia, B.; Sameoto, D. Strong, reversible underwater adhesion via gecko-inspired hydrophobic fibers. ACS Appl. Mater. Inter. 2014, 6, 21995-22003. [CrossRef] [PubMed]

5. Jena, R.K.; Yue, C.Y.; Lam, Y.C.; Tang, P.S.; Gupta, A. Comparison of different molds (epoxy, polymer and silicon) for microfabrication by hot embossing technique. Sens. Actuators B Chem. 2012, 163, $233-241$. [CrossRef] 
6. Lopera, S.; Mansano, R.D. Plasma-based surface modification of polydimethylsiloxane for PDMS-PDMS molding. ISRN Polym. Sci. 2012, 2012, 1-5. [CrossRef]

7. McDonald, J.C.; Whitesides, G.M. Poly (dimethylsiloxane) as a material for fabricating microfluidic devices. Acc. Chem. Res. 2002, 35, 491-499. [CrossRef] [PubMed]

8. Liu, C. Recent developments in polymer MEMS. Adv. Mater. 2007, 19, 3783-3790. [CrossRef]

9. Choi, W.M.; Park, O.O. A soft-imprint technique for direct fabrication of submicron scale patterns using a surface-modified PDMS mold. Microelectron. Eng. 2003, 70, 131-136. [CrossRef]

10. Romenesko, D.J.; Chorvath, I.; Olsen, C.W.; Tonge, L.M. Poly (fluorosilicones). In Kirk-Othmer Encyclopedia of Chemical Technology; Wiley \& Sons: New York, NY, USA, 2005.

11. Koford, S.K.; Allied Corp. Fluorosilicone Elastomers, Method of Making such Elastomers and Electrical Connectors Including the Elastomers. U.S. Patent 4,488,771, 18 December 1984.

12. Fukuda, T.; Fukushima, M.; Itoh, K.; Fujiki, H. Fluorosilicone Rubber Composition. U.S. Patent 4,988,758, 29 January 1991.

13. Osawa, Y. Method for Producing Molded Fluoroelastomer Parts. U.S. Patent 6,468,463, 22 October 2002.

14. Uno, T.; Takita, K.; Sekiguchi, S.; Shin-Etsu Chemical Co Ltd. Fluorosilicone rubber composition and molded rubber article. U.S. Patent 7,510,772, 31 March 2009.

15. Itami, Y.; Mitsuhashi, H.; Masutani, T.; Hupfield, P.C.; Kleyer, D.L. Fluorosilicone Mold Release Composition. U.S. Patent 8,497,340, 30 July 2013.

16. Kikuchi, S. Three-dimensional Molding Device. U.S. Patent 7,780,429, 24 August 2010.

17. Yamana, M.; Nakamae, Y.; Sakashita, H.; Kashiwagi, M. Mold Release Agent, Cured Film Obtained from Said Mold Release Agent, and Molding Method Using Said Mold Release Agent. U.S. Patent 5,804,674, 8 September 1998.

18. Takamizawa, M.; Fujisawa, T.; Shiotani, S.; Futaki, K. Process of Molding a Coated Plastic Lens. U.S. Patent 5,096,626, 17 March 1992.

19. Klemm, K.A.; Fairbank, J.A. Method for Preparing a Mold Part Useful for Transferring a Coating onto an Optical Substrate. U.S. Patent 6,986,857, 17 January 2006.

20. $\quad$ Eckberg, R.P.; Evans, E.R.; Toub, M.R. Fluorosilicone Coatings. U.S. Patent 5,616,403, 1 April 1997.

21. Park, B.C. An Evaluation of a Fluorosilicone Elastomer Used as a Dynamic Seal in the LANCE Propulsion System (No. RL-76-2); Army Missile Research Development and Engineering Lab. Redstone Arsenal Ala Ground Equipment/Materials Directorate: Huntsville, AL, USA, 1975.

22. Stritzke, B. Custom Molding of Thermoset Elastomers: A Comprehensive Approach to Materials, Mold Design, and Processing; Carl Hanser Verlag GmbH: München, Germany, 2012.

23. Technical Data Sheet of SYLGARD ${ }^{\mathrm{TM}} 184$ Silicone Elastomer. Available online: https:/ / consumer.dow.com/ content/dam/dcc/documents/en-us/productdatasheet/11/11-31/11-3184-sylgard-184-elastomer.pdf? iframe=true (accessed on 26 June 2018).

24. Dow Corning ${ }^{\circledR 5-8601 ~ F l u o r o s i l i c o n e ~ L i q u i d ~ S i l i c o n e ~ R u b b e r . ~ A v a i l a b l e ~ o n l i n e: ~ h t t p s: / / c o n s u m e r . d o w . ~}$ com/en-us/document-viewer.html?ramdomVar=118780221716818847\&docPath=/ content/dam/dcc / documents/en-us/productdatasheet/45/45-158-dow-corning-5-8601-fluorosilicone-liquid-rubber.pdf (accessed on 26 June 2018).

25. Flitney, B. Extending the application of fluorosilicone elastomers. Seal. Technol. 2005, 2, 6-11. [CrossRef]

26. Dawir, M. Sealing in the automotive industry with liquid fluorosilicone elastomers. Seal. Technol. 2008, 7, 10-14. [CrossRef]

27. Ferguson, B.J. Improved Gecko Inspired Dry Adhesives Applied to the Packaging of MEMS. Master's Thesis, University of Alberta, Edmonton, AB, Canada, June 2013.

28. Wang, Y.; Lehmann, S.; Shao, J.; Sameoto, D. Adhesion circle: A new approach to better characterize directional gecko-inspired dry adhesives. ACS Appl. Mater. Interfaces 2017, 9, 3060-3067. [CrossRef] [PubMed]

29. Mäkelä, T.; Haatainen, T.; Majander, P.; Ahopelto, J. Continuous roll to roll nanoimprinting of inherently conducting polyaniline. Microelectron. Eng. 2007, 84, 877-879. [CrossRef]

(C) 2018 by the authors. Licensee MDPI, Basel, Switzerland. This article is an open access article distributed under the terms and conditions of the Creative Commons Attribution (CC BY) license (http:/ / creativecommons.org/licenses/by/4.0/). 